\title{
UNIVERSIDADES PÚBLICAS E AS POLÍTICAS DE ESPORTE E LAZER
}

Recebido em: 19/10/2011

Aceito em: 18/06/2012

\author{
Gabriela Machado Ribeiro ${ }^{1}$ \\ Elizara Carolina Marin ${ }^{2}$
}

Universidade Federal de Santa Maria

Santa Maria - RS - Brasil

RESUMO: Este trabalho visa apresentar um panorama inicial do modo como as universidades públicas brasileiras têm compreendido as manifestações de esporte e lazer na formulação de suas políticas institucionais. Por meio de pesquisa bibliográfica e documental, procuramos discutir a constituição da universidade pública no Brasil, sua função social e relação tanto com as manifestações de esporte e lazer quanto com as propostas de esporte e lazer dos documentos oficiais. Para dar conta de tais objetivos buscamos identificar de que forma as questões relativas a essas manifestações são contempladas nos documentos oficiais, tais como PPIs, PDIs e projetos REUNI. Podese dizer que as universidades fazem alusões a esporte e lazer em suas proposições, mencionando, majoritariamente, a necessidade de apoiar, incentivar tais manifestações sem, contudo, sinalizarem que tipos de atividades se referem e sem prever propostas objetivas.

PALAVRAS CHAVE: Esportes. Atividades de Lazer. Políticas Públicas.

\section{PUBLIC UNIVERSITIES AND THE POLITICS OF SPORT AND LEISURE}

ABSTRACT: This paper aims to present an initial overview of how Brazil's public universities have understood the manifestations of Sport and Recreation in the formulation of institutional policies. Through literature review and documentary discusses the way of incorporating public university in Brazil, its social function and its relationship to both the manifestations of Sport and Recreation regarding the proposals for Sport and Recreation in official documents. To accomplish the objectives aims to identify how the issues associated with these events are discussed in official documents, such as PPIs, PDIs and projects REUNI. You could say that universities make to the Sport and Recreation citations in their proposals, citing mainly from the need to support, encourage such manifestations. However, left to indicate what types of activities they cover, without providing target proposals.

KEYWORDS: Sports. Leisure Activities. Public Policies.

\footnotetext{
${ }^{1}$ Acadêmica do curso de Mestrado em Educação Física ESEF/UFPel, bolsista CAPES.

2 Professora Adjunta da UFSM, colaboradora do Programa de Pós-Graduação da ESEF/ UFPel e orientadora da pesquisa em questão.
} 


\section{Considerações Iniciais}

O papel das universidades enquanto promotora de políticas e concretizadora de ações no âmbito do esporte e lazer é uma temática ainda pouco pesquisada na área dos estudos do lazer.

A universidade, enquanto instituição social, não fica alheia à estrutura social e aos valores perpetuados pela sociedade civil e por seus órgãos mantenedores. Em meio a inúmeros conflitos de interesses as universidades públicas também elegem prioridades as quais são expressas na definição de sua missão e na elaboração de suas políticas institucionais e das metas a serem alcançadas.

Cientes de tais implicações, as autoras procuram neste trabalho subsidiar a compreensão da universidade pública enquanto promotora de atividades de esporte e lazer e apresentar um panorama inicial da maneira como as universidades públicas brasileiras têm compreendido as manifestações de esporte e lazer na formulação de suas políticas de desenvolvimento institucional, na proposta pedagógica, entre outros.

Partindo do princípio de que o lazer se configura como uma via de emancipação, vivenciada no tempo livre, com grande potencial de formação e educação humana, entende-se que o acesso aos bens sociais e culturais faz parte da formação cidadã do sujeito e que esporte e lazer na universidade devem emergir como vivências significativas à formação humana. Cabe ressaltar que a compreensão da dimensão educativa do lazer pode viabilizar a formação de sujeitos com uma postura crítica frente aos produtos da indústria cultural e conduzir à compreensão da necessidade de se reivindicar políticas públicas de esporte e lazer.

A partir de tais pressupostos surge um conjunto de questionamentos: "Qual é a função da universidade pública?”; "Qual o papel da universidade no que tange a 
políticas de esporte e lazer?”; "Como o esporte e o lazer são contemplados nos

documentos oficiais que regem as universidades?”.

\section{Caminhos metodológicos}

Para identificar o investimento das universidades públicas brasileiras em políticas de esporte e lazer e o teor das propostas existentes, recorremos, após consultar as orientações legais do MEC para as universidades, aos Planos de Desenvolvimento Institucional (PDI), aos Projetos Político Pedagógico (PPI) e aos Planos de Reestruturação e Expansão das Universidades Federais (REUNI) e subjacentes (Leis, Decretos, Pareceres que os instituem, e os regulamentam), como fontes primordiais para a compreensão de tal entendimento ${ }^{3}$.

A opção pela leitura e análise desses documentos se deu em função de que, além de ser condição indispensável para credenciamento e/ou recredenciamento das IES junto ao MEC, o PDI juntamente com o PPI são partes integrantes do processo avaliativo do SINAES $^{4}$, e através de sua redação é que esses documentos buscam expressar a identidade de cada instituição. O PDI "é o documento que identifica a Instituição de Ensino Superior (IES), no que diz respeito à sua filosofia de trabalho, à missão a que se

\footnotetext{
${ }^{3}$ No período de janeiro de 2010 a outubro de 2010 foram acessados os sites das 58 (cinqüenta e oito) universidades federais brasileiras em busca da localização dos documentos elencados. Essa etapa foi permeada por alguns percalços, pois são poucos os sites que apresentam links para acesso aos documentos em sua página inicial. Foi necessária uma exaustiva procura nos links das Pró-Reitorias, no rol dos documentos e nas ferramentas de busca de cada site. Diversas instituições deixam disponíveis apenas alguns dos documentos selecionados para este estudo. Todavia, definimos como critério de análise apenas as instituições que disponibilizam três dos documentos listados (PDI, PPI e plano REUNI) que fazem parte do corpus. Assim, 15 (quinze) universidades federais (UTFPR; UFPR; UFSC; FURG; UFSM;UNIFESP; UFMG; UFV; UNIRIO; UFT;UFBA; UFPB; UFAL;UFRPE; UFMS ) fazem parte do elenco de instituições pesquisadas.

${ }^{4}$ SINAES é o Sistema Nacional de Avaliação da Educação Superior que tem como finalidade promover "a melhoria da qualidade da educação superior, a orientação da expansão da sua oferta, o aumento permanente da sua eficácia institucional e efetividade acadêmica e social e, especialmente, a promoção do aprofundamento dos compromissos e responsabilidades sociais das instituições de educação superior, por meio da valorização de sua missão pública, da promoção dos valores democráticos, do respeito à diferença e à diversidade, da afirmação da autonomia e da identidade institucional". (BRASIL, 2004).
} 
propõe, às diretrizes pedagógicas que orientam suas ações, à sua estrutura organizacional e às atividades acadêmicas que desenvolve e/ou que pretende desenvolver" (BRASIL, 2004) ${ }^{5}$. E o PPI é um instrumento político, filosófico e teóricometodológico que orienta as práticas acadêmicas da IES, tendo em vista sua trajetória histórica, inserção regional, vocação, missão, visão e objetivos gerais e específicos. O PPI revela uma visão de mundo e do papel da educação superior, ao mesmo tempo em que explicita o papel da IES e sua contribuição social nos âmbitos local, regional e nacional, por meio do ensino, da pesquisa e da extensão na busca entre o real e o desejável que deve delinear o horizonte de médio e longo prazo, não se limitando, portanto, a um período de gestão.

Além dos documentos citados, o programa REUNI foi selecionado como fonte de análise por ser um plano recente do governo federal que tem ocasionado modificações significativas na estrutura e no funcionamento das IES. Com o objetivo de criar condições para a ampliação do acesso e permanência na educação superior, no nível de graduação, pelo melhor aproveitamento da estrutura física e de recursos humanos existentes nas universidades federais, o referido plano, após o primeiro ano de implantação pelo MEC, havia conquistado a adesão da totalidade das instituições existentes até esse momento ${ }^{6}$.

\section{A universidade pública}

Tal como se apresenta hoje, a universidade teve sua trajetória marcada por confrontos, disputas e alianças entre diferentes grupos sociais. Acompanhando as

\footnotetext{
${ }^{5}$ Lei n. ${ }^{\circ} 10.861 / 04$, de 14 de abril de 2004. Disponível em: http://portal.mec.gov.br/arquivos/pdf/leisinaes.pdf. Acesso em: 10 de out. 2010.

6 Dados do relatório do Primeiro ano do REUNI, disponíveis em: http://reuni.mec.gov.br Acesso em: 10 de out. 2010 .
} 
diversas transformações ocorridas desde a sua criação, foi forjando sua identidade conforme lhe fora demandado. Assim, após passar pela égide da igreja no período de sua criação no século XII, de receber os impactos do período Renascentista calcado no humanismo literário e artístico do século $\mathrm{XV}$, de institucionalizar a ciência a partir das descobertas científicas do século XVII e das influências iluministas do século XVIII, se consolida com um modelo universal laicizado no século XIX. Atualmente, encontra-se no bojo de um emaranhado de determinações neoliberais.

O novo modelo de universidade que emergiu e vem se estabelecendo nas últimas décadas apresenta-se amparado pelo estabelecimento da ciência e da inovação tecnológica como sinônimos de eficácia e parâmetro de competitividade. Essa nova configuração gera a necessidade de definir novas finalidades, deixando as universidades cada vez mais "coagidas a transitarem de um referencial mais acadêmico, em que a educação superior é vista como bem público e direito social, para um referencial economicista, baseado numa visão que acentua o pragmatismo, a competição e a privatização" (FERREIRA, 2010, p.2).

Há que se considerar, no entanto, que essa mudança de função social não acontece repentinamente,

\footnotetext{
A transformação da educação superior numa mercadoria educacional é um objetivo de longo prazo e esse horizonte é essencial para compreender a intensificação da transnacionalização desse mercado atualmente em curso. Desde 2000, a transnacionalização neoliberal da universidade ocorre sob a égide da Organização Mundial do Comércio no âmbito do Acordo Geral sobre o Comércio de Serviços (GATS). A educação é um dos doze serviços abrangidos por este acordo e o objetivo deste é promover a liberalização do comércio de serviços através da eliminação, progressiva e sistemática, das barreiras comerciais. O GATS transformou-se em pouco tempo num dos temas mais polêmicos da educação superior, envolvendo políticos, universitários e empresários (SANTOS, 2010, p.33).
} 
A instituição de novos papéis para as universidades é, em parte, saldo do processo de transnacionalização do mercado universitário que vê o sistema educacional tal qual uma incubadora de novos serviços; que aposta na exacerbação do capital humano como condição de aumento da eficácia e da empregabilidade; que entende a universidade como prestadora de serviço à sociedade da informação e à economia do conhecimento; que estimula a flexibilidade e a adaptabilidade às expectativas dos empregadores e à substituição do paradigma institucional pelo paradigma empresarial. Essas premissas, que constituem a proposta de reforma educacional do Banco Mundial, seriam viabilizadas por aquilo que o Acordo Geral sobre o Comércio de Serviços (GATS) chama de "modos de oferta transnacional de serviços universitários mercantis: oferta transfronteiriça; consumo no estrangeiro; presença comercial; presença de pessoas" (SANTOS, 2010, p.34).

As políticas educacionais adotadas pela União Européia têm evidenciado medidas para a concretização dessas ideias revelando-se um autêntico locus supranacional, em especial no que tange ao âmbito universitário. Vislumbrando a constituição de um espaço europeu de educação superior capaz de competir com o sistema de ensino norte-americano, institui um processo político de reformas institucionais denominado Processo de Bolonha ${ }^{7}$.

No Brasil, ações concernentes ao ensino superior têm evidenciado grande aproximação com os princípios da Declaração de Bolonha ao evidenciar preocupação em expandir as relações internacionais no âmbito universitário e enfatizar o ensino superior como estratégia de desenvolvimento.

\footnotetext{
${ }^{7}$ A Declaração de Bolonha, assinada em 19 de junho de 1999, em Bolonha (Itália), assume como meta para a década seguinte consolidar "um espaço europeu de educação superior coerente, compatível, competitivo e atrativo para estudantes europeus e de países terceiros". Para um maior aprofundamento do assunto ver Catani, Lima e Azevedo (2008).
} 
Suely Ferreira salienta que tanto no governo Fernando Henrique Cardoso (FHC) quanto no governo de Luis Inácio Lula da Silva (Lula) o ensino superior ocupou lugar estratégico no desenvolvimento da região em que as IES estão inseridas e, consequentemente, da nação. Para atender tal propósito, FHC fomentou a expansão da iniciativa privada e o aumento da competitividade entre as IES mediante o processo de avaliação, enquanto Lula concretizou essa meta através da criação de novas universidades; difusão da EAD pela criação da Universidade Aberta do Brasil; implementação do Programa Universidade para Todos e do Programa de Apoio a Planos de Reestruturação e Expansão das Universidades Federais - REUNI. (FERREIRA, 2010).

O REUNI estabelece como diretrizes a serem cumpridas em cinco anos o aumento do número de alunos para cada professor; a redução da evasão e o aumento das taxas de conclusão; a ampliação da mobilidade estudantil; a revisão da estrutura curricular e a diversificação das modalidades de educação.

Apesar de aparentemente representar uma iniciativa exclusivamente benéfica, está gerando efeitos devastadores nas universidades públicas. Historicamente, consideradas centros de excelência, as IES públicas põem em xeque essa tradição ao aderirem a essa proposta que, entre outras consequências, tem intensificado a precarização da formação profissional e do trabalho docente.

Sob a incumbência de expandir, as IES têm aumentado o número de alunos por turma, criado cursos de curta duração, representando uma formação aligeirada e desvinculada da pesquisa e da extensão. Por conseguinte, os professores têm mais horas/aula, atendem a mais alunos em sala de aula e diminuem seu tempo de dedicação às atividades de pesquisa e extensão. 
Lima (2009, p.4) alerta para o fato de que a dinâmica de contratação de professores nas universidades está pautada no "banco de professores-equivalentes", em que para cada docente é atribuído um peso diferenciado conforme seu regime de trabalho. Nessa lógica, as ações governamentais incitam as universidades federais a contratar professores em regime de trabalho de 20 horas para o trabalho em sala de aula, "esvaziando o sentido do regime de trabalho em dedicação exclusiva, base de realização da indissociabilidade entre ensino, pesquisa e extensão”. Assim, esse princípio que já vinha evidenciando desmantelamento nas universidades públicas desde a disseminação do entendimento de ensino gratuito restrito à graduação e à pós-graduação stricto $\operatorname{sensu}^{8}$, possibilitando a oferta legal de cursos de extensão e pós-graduação lato sensu pagos, os quais se convertem oficialmente em fonte de arrecadação de recursos.

Legalmente, nesse contexto, torna-se ainda mais tênue a distinção entre público e privado ao se expandir à oferta de cursos pagos de pós-graduação, de extensão e serviços prestados à comunidade, desvirtuando o entendimento de extensão como meio de socializar conhecimentos e ações das universidades públicas com a comunidade.

O desenvolvimento da extensão, que outrora fora o cerne da relação entre universidade e comunidade, deve ser amplamente debatido à medida que vem sofrendo paulatinamente a desfiguração do seu papel enquanto principal forma de interação com a sociedade.

\section{Notas sobre a Universidade e Lazer: perspectivas teóricas e desafios institucionais}

Compreendendo a universidade como instituição que tem entre suas funções a de socializar o conhecimento histórico e culturalmente acumulado e refletir sobre os

\footnotetext{
${ }^{8}$ Proposta do PL n. ${ }^{\circ} 7200 / 2006$ enviado ao Congresso Nacional, apensado no PL n. ${ }^{\circ} 4214 / 04$ e no PL n. ${ }^{\circ} 4221 / 04$, disponível em: http://www.camara.gov.br/sileg/prop_detalhe.asp?id=327390. Acesso em: 20 dez. 2010.
} 
significados sociais que emergem de questões decorrentes da realidade social, buscamos tecer aproximações entre o papel da universidade pública e o direito do cidadão ao acesso e usufruto das manifestações de esporte e lazer.

Viabilizar a democratização do esporte e do lazer, conforme enuncia Amaral (2006, p.170), perpassa pela reflexão das e acerca das "políticas públicas de lazer questionando os modelos pautados no controle, no assistencialismo e no consumo". A autora adverte sobre a necessidade de pensar um tempo em que a população possa usufruir atividades que ajudem a desenvolver a criticidade, o gosto estético, um senso ético, e que supere os padrões estereotipados e veiculados pela sociedade do consumo.

Nessa direção, Muller e Surel (2002), ao tecerem esclarecimentos sobre políticas públicas, explicam que essas são constituídas por um conjunto de medidas concretas que constituem o conteúdo visível da política. São compostas por um conjunto diversificado de ações que envolvem um número significativo de atores advindos de diferentes organizações, públicas ou privadas, que intervêm em diferentes níveis. Essas características podem contribuir com o caráter contraditório que a ação política frequentemente protagoniza.

A questão da coerência e/ou de demonstração da preocupação estatal com um dado setor, em geral, é aferida através dos recursos financeiros dedicados a esse setor pelo Estado. Conforme destacam os autores, "somos tentados a nos ater a um indicador orçamentário e, particularmente, a considerar que uma política será um tanto mais eficaz quanto mais elevados forem os créditos que lhe são destinados” (MULLER e SUREL, 2002, p.12). 
Os mesmos autores, todavia, sinalizam que não é somente esse tipo de recurso que constitui o conteúdo e a eficácia de uma política pública. Acenam que devem ser ponderados:

[...] recursos financeiros (os créditos atribuídos aos ministérios), intelectuais (a competência que os atores das políticas são capazes de mobilizar), reguladores (o fato de elaborar uma nova regulamentação constitui um recurso novo para os tomadores de decisão), materiais. Ela é também constituída de produtos, isto é, de outputs reguladores (normativos), financeiros, físicos. (MULLER e SUREL, 2002, p.14).

No que concerne às políticas de esporte e lazer, Marcellino (2006, p.85) apresenta um entendimento semelhante ao de Muller e Surel (2002), acenando com a necessidade de ser garantido um investimento orçamentário para viabilizar "planejamento, construção, administração e animação dos equipamentos para uma política de democratização cultural”. Assim, define que toda política pública de esporte e lazer deve prever financiamento, espaços/equipamentos, animação sociocultural e divulgação.

No que tange a essa temática, a questão orçamentária é um aspecto bastante delicado. Em primeiro lugar, porque historicamente, conforme sinaliza Amaral (2006, p.169), as questões relacionadas ao lazer têm sido atribuídas, de maneira geral, a secretarias ou ministérios do esporte. Essa vinculação atribui ao lazer um caráter de apêndice do esporte. "As políticas de lazer não são centrais, muito menos a destinação de verbas para a implantação de projetos sociais, e percebe-se menos ainda a existência do entendimento de que este seja um fenômeno multidisciplinar". Em segundo lugar, porque os recursos utilizados para financiar os gastos governamentais, distribuídos entre grupos sociais diferenciados ou setores da sociedade civil, como no caso do esporte, são apropriados pelo Estado por intermédio de tributação. Nessa lógica, a fração do orçamento sobre a qual o Executivo e o Legislativo podem deliberar é muito pequena 
(apenas $10 \%$ do total), tornando mais dificultoso aumentar os recursos para o esporte e lazer, a menos que fossem criadas outras formas de gerar proventos, o que poderia implicar a "criação de mais impostos ou realocação de recursos de fontes de outras áreas" (VERONEZ, 2005, p.317).

Almeida e Marchi Jr. (2010), ao estudarem as prioridades governamentais no que se refere aos investimentos financeiros, analisam quanto foi destinado aos programas de esporte e lazer diretamente pelo governo federal e através de repasses aos estados e municípios no período entre 2004 e 2008. Segundo a análise dos pesquisadores, o Ministério do Esporte investiu 72\% no Rio'2007 e pouco menos de 7\% da verba foi direcionada para ações relacionadas ao esporte participação e educacional. Nesse período, o somatório de investimentos do Ministério do Esporte e outros ministérios em esporte de rendimento totalizaram $81 \%$, com menos de $8 \%$ para as manifestações de esporte educacional e participação. Atentam, todavia, para o fato de que esse quadro se inverte em relação à transferência de recursos aos estados e municípios, totalizando $61 \%$ dos recursos investidos em programas das manifestações do esporte participação e educacional e $29 \%$ em ações de esporte de rendimento.

Contudo, a pesquisa ilustra que, apesar desses investimentos em esporte educacional e de participação, no balanço geral, o maior investimento do governo federal foi na realização do Rio 2007, totalizando R\$975 milhões. Seguidos a este, o Programa "Esporte e Lazer na Cidade" com aproximadamente R\$730 milhões, o programa "Vivência e Iniciação Esportiva Educacional - Segundo Tempo", com quase R\$460 milhões, e o programa "Brasil no Esporte de Alto Rendimento", que teve de verba mais de R $\$ 175$ milhões (ALMEIDA e MARCHI JR, 2010, p.85). 
Os dados oriundos de tais pesquisas remetem ao questionamento acerca das prioridades do Estado no que tange ao investimento em manifestações do esporte. As informações levantadas acenam para a compreensão de que, ao priorizar o esporte de rendimento, o princípio constitucional que prevê no art. 217 “[...] a destinação de recursos públicos para a promoção prioritária do desporto educacional e, em casos específicos, para a do desporto de alto rendimento" (BRASIL, 1988) é ferido em sua essência.

Ao tratar de outro aspecto concernente às políticas públicas de esporte e lazer, Marcellino (2006) enfatiza a necessidade de democratizar espaços e equipamentos culturais ${ }^{9}$. O Perfil dos Municípios (IBGE, 2007), ao apresentar informações acerca da cultura no país, referentes ao ano de 2006, no que refere à disponibilidade desses equipamentos ${ }^{10}$, acena que $97,8 \%$ dos municípios têm biblioteca pública, $94,1 \%$ estádio e/ou ginásios poliesportivos, $89,5 \%$ centros culturais, $79,4 \%$ museus e $76,8 \%$ teatro ou salas de espetáculo. Ao se considerar os dados brutos, emerge a falsa impressão de que há uma democratização dos bens culturais. O próprio documento, entretanto, adverte que os índices refletem apenas a existência do equipamento sem aprofundar informações acerca das condições de uso e disponibilidade de utilização pela população. Elucida, ainda, que os dados levantados ilustram o clássico processo das desigualdades espaciais existentes no país. Os bens culturais, conforme indicam os índices, existem em maior número nas regiões Sul $(5,7 \%)$, Sudeste $(5,6 \%)$ e Centro-Oeste $(5,2 \%)$ e em

\footnotetext{
${ }^{9}$ MARCELLINO (2006), compreende espaço e equipamento como conceitos distintos, enfatizando que o espaço é o suporte para os equipamentos e, por conseguinte, os equipamentos organizam o espaço em função de uma atividade.

${ }^{10}$ Segundo a definição adotada pelo IBGE, os equipamentos culturais constituem o estoque fixo ligado às culturas existentes no município, aberto ao público, podendo ser mantido pela iniciativa privada ou pelo poder público de qualquer esfera (federal, estadual ou municipal) (IBGE, 2007, p. 15). É considerada a existência de 13 equipamentos e meios de comunicação bibliotecas públicas; videolocadoras; estádios ou ginásios poliesportivos; lojas de venda de discos, fitas, CD e DVD; estações de rádio FM; estações de rádio AM; provedores de Internet; livrarias; museus; teatros ou salas de espetáculos; geradoras de TV; cinemas; shopping center (IBGE, 2007, p.101).
} 
menor número nas regiões do Nordeste $(4,5 \%)$ e Norte $(4,3 \%)$. Em relação ao porte populacional dos municípios, a disponibilidade de bens culturais concentra-se nos grandes centros e municípios com mais de 500 mil habitantes, alcançando o percentual de $12,3 \%$, enquanto que nos municípios com até 5 mil habitantes esse índice é de 3,1\% (IBGE, 2007, p.109).

Diante do quadro de escassez de equipamentos específicos para o lazer, Marcellino (2006, p.80) sinaliza que a democratização do acesso e usufruto das manifestações culturais não "pode depender unicamente da construção desses". Reitera que eles são importantes, e que sua disseminação deve estar na pauta das ações governamentais; todavia, "a ação democratizadora precisa abranger a conservação dos equipamentos já existentes, sua divulgação, dessacralização, e incentivo à utilização através de políticas específicas, e da preservação do patrimônio ambiental urbano".

Outro elemento que merece atenção, segundo o autor, é a implementação e sustentação de uma proposta de animação sociocultural consistente. A participação e o intermédio de profissionais capacitados na socialização das práticas lúdicas e culturais pode, em última instância, garantir as qualidades técnicas requeridas a cada manifestação e às especificidades da área.

Cabe salientar que os aspectos apresentados até então contribuirão muito pouco com a democratização do acesso às manifestações culturais se as políticas desenvolvidas estiverem dissociadas de políticas sociais que garantam ao sujeito o exercício pleno de sua cidadania. Para que realmente se efetive uma política de lazer é imprescindível repensar a organização do mundo do trabalho e suas exaustivas jornadas semanais; um reordenamento urbano que, dentre outras coisas, preveja especialmente 
condições dignas de moradia; e ainda ações consistentes de formação e desenvolvimento profissional.

\section{Espaços de Lazer: desvendando possibilidades}

$\mathrm{Na}$ atual organização urbano-espacial, em que proliferam shopping center e espaços artificiais privados como símbolos do lazer-mercadoria, em que diminui a disponibilidade de equipamentos coletivos públicos, urge a necessidade de criar alternativas de contraposição à face excludente dessa configuração.

Ao discorrer sobre espaço e lazer na sociedade moderna, Rodrigues (2002, p.157), além de denunciar a privatização ilegal de espaços públicos naturais (praias, áreas verdes, morros, etc.), aponta que os shoppings centers estão assumindo a função das antigas ruas e praças como locus de sociabilidade. A implantação artificial desses espaços, todavia, falseia uma sociabilidade desprovida da espontaneidade social, advinda do uso compartilhado quotidianamente. $\mathrm{O}$ autor explica que nesses espaços as práticas sociais se revelam desprovidas do "sentimento de pertencimento, não expressando vínculos identitários que caracterizam o lugar ${ }^{11}$ ".

Considerando o caráter segregador desse cenário, em que os espaços de lazer são privilégio da minoria, Marcellino (2008), afirma que não se pode esperar apenas pela iniciativa governamental. Há necessidade de vitalizar espaços públicos já existentes e otimizar espaços públicos não específicos, ou seja, equipamentos não construídos de modo particular para essa função, mas que podem incorporá-la na sua dinâmica. O autor destaca como expoentes dessa categoria os bares ${ }^{12}$, as ruas, as escolas, etc.

\footnotetext{
${ }^{11} \mathrm{O}$ autor utiliza o termo 'lugar' como sinônimo de 'espaço vivido', do mundo experienciado.

12 Marcellino (2008, p.18), refere-se aqui ao bar com características dos tradicionais botequins, como local de encontro, de jogar conversa fora, modelo contrário ao daquele que se figura hoje.
} 
Direcionando o foco da pesquisa para as possibilidades da escola, retoma-se Marcellino (2006), autor que atribui ao espaço escolar um grande potencial, argumentando que as escolas oferecem diversas opções para o lazer, uma vez que dispõem de estrutura física (salas, quadras, pátios, auditórios) capaz de abrigar vivências nos vários campos de interesse. Além disso, estabelecem vínculos estreitos com a comunidade no entorno, apresentando-se nos dias não letivos (férias, finais de semana e feriados) como espaço de promoção e usufruto de atividades lúdicas e esportivas.

Paro (1995) contribui com o debate enfatizando que a escola pública, ao incorporar sua função educativa global precisa abarcar outras formas educativas para além da educação formal. Compreende que a educação é responsável pela atualização histórico-cultural dos sujeitos e como expressão do comprometimento com a superação da inadmissível injustiça social, a escola precisa formar cidadãos atualizados, capazes de participar politicamente, usufruindo aquilo que o homem histórico produziu e contribuindo com seu potencial criador e transformador na sociedade atual. Enfatiza que, somente estando aberta a outras práticas sociais, em especial ao lazer, como expressão da possibilidade de emancipação humana, a escola participará de forma efetiva na necessária reforma intelectual e moral.

A otimização da escola como espaço de lazer pode significar a apreensão do bem público pela comunidade, e configurar um sentimento de pertença da escola pela população. Nessa direção, Paro (1995) afirma que:

[...] uma das formas de se aferir a intensidade das relações entre a escola pública e a comunidade é a dimensão em que o espaço escolar é utilizado pelos usuários nos períodos em que a escola não desenvolve suas atividades docentes regulares, especialmente nos fins de semana, nos feriados e nas férias escolares. Nos bairros ocupados pelas camadas populares, nas periferias dos grandes centros urbanos, como São Paulo, os equipamentos coletivos de lazer, como teatro, cinema, museus, clubes esportivos ou recreativos, etc. são 
extremamente escassos ou simplesmente não existem. Mesmo os poucos terrenos vazios onde se dão as peladas aos fins de semana ou os galpões em que se realiza alguma festa ou comemoração vão sendo eliminados com a ocupação mais intensa do solo, provocada pela crescente urbanização. Diante disso, o prédio e as dependências da escola pública poderiam ser uma alternativa para o desenvolvimento de alguma atividade de lazer que contribuísse para minorar a falta de opção da população nesse sentido (PARO, 1995, p.314).

Aproximando as considerações feitas por Marcellino (2008) e Paro (1995) sobre

o espaço da escola pública, ao espaço da Universidade, podemos afirmar que essa também se constitui um espaço/equipamento não específico de lazer. Considerando que as IES constituem um lócus de produção e disseminação da cultura historicamente produzida, que tem instalações semelhantes e possibilidades no campo do lazer tão ricas quanto às da escola, pode-se dizer que as universidades necessitam repensar suas ações e refletir sobre sua responsabilidade no que tange à democratização cultural através da promoção de espaços/tempo de vivência de esporte e lazer.

As considerações feitas sobre as semelhanças entre universidades e escola básica são pertinentes, sobretudo porque ambas as instituições ocupam-se, legalmente, da educação formal dos sujeitos. Essas aproximações, no entanto, devem ponderar acerca das especificidades de cada instituição e do papel que assumem no contexto em que estão inseridas.

Data de longo tempo a relação das universidades brasileiras com as manifestações de esporte e lazer, protagonizando, portanto, diferentes configurações e atribuições. Dessa forma, para problematizar o fomento dessas manifestações no âmbito universitário, parece primordial compreender sua dinamização histórica para fundamentar a discussão de suas potencialidades na atualidade.

\section{Esporte e Lazer na Universidade}


Ao buscar reconstruir a trajetória das manifestações de esporte e lazer no âmbito universitário através da consulta em livros, pesquisas e publicações sobre a temática, encontram-se indícios que remontam, basicamente, ao caráter e às manifestações de cunho esportivo e competitivo.

$\mathrm{Na}$ ausência de evidências que indiquem outra forma de manifestações nos primórdios da universidade brasileira, Starepravo $(2005)^{13}$ sinaliza que as manifestações esportivas no âmbito universitário brasileiro tiveram início no "final do séc. XIX no College Mackenzie em São Paulo, na Faculdade de Medicina e Cirurgia, localizada na Praia Vermelha (Rio de Janeiro), e na antiga Escola Politécnica do Rio de Janeiro". O autor destaca que no início do século XX o esporte universitário foi impulsionado por clubes de futebol carioca como Botafogo, Flamengo e Fluminense.

Conforme elucida Starepravo (2005) em dados publicados na revista da Confederação Brasileira de Desporto Universitário ${ }^{14}$, o desporto universitário assinala em 1916 as primeiras disputas interestaduais entre faculdades do Rio de Janeiro e São Paulo. Na esfera internacional destaca-se a realização dos primeiros jogos mundiais universitários.

No início dos anos 1930, as confederações esportivas estudantis começam se regulamentar. No Rio de Janeiro é legalizada a Federação Atlética dos Estudantes em 1933 e, em 1934, em São Paulo, a Federação Universitária Paulista de Esportes.

Em 1939, durante a realização do Congresso Nacional de Estudantes, realizado no Rio de Janeiro, representantes das diversas federações e agremiações universitárias de esporte resolvem fundar a Confederação Universitária Brasileira de Esporte (CUBE), que, já no ano seguinte, é renomeada para Confederação Brasileira do Desporto

\footnotetext{
${ }^{13} \mathrm{O}$ autor baseou-se em dados publicados no Caderno de Esportes do Jornal Diário do Pará em 18 de julho de 1987.

${ }^{14}$ Disponível em: < $\underline{\text { http://www.cbdu.org.br/revistas }}>$. Acesso em: 15 jul.2010.
} 
Universitário (CBDU), com o intuito de agregar todas as entidades esportivas universitárias existentes até então.

Starepravo (2005) relembra que até a década de 1940, tanto as organizações em federações quanto a realização de eventos esportivos na universidade se deram de forma espontânea e sem a intervenção do Estado. Todavia, com a promulgação do Decreto-Lei n. ${ }^{3} 3.617$, de 15 de setembro de 1941, que regulamentava o esporte universitário brasileiro, o governo passa a intervir diretamente. $\mathrm{O}$ autor chama atenção para que, antes dessa lei, foi estabelecido o Decreto-Lei n. ${ }^{\circ} 421$ de 1938 , que dá início à intervenção do Estado com o intuito de incentivar o esporte universitário brasileiro. $\mathrm{O}$ Decreto-Lei exigia que as universidades e estabelecimentos isolados de ensino superior deveriam construir e montar praças esportivas para seus alunos, sendo uma das condições para autorização e reconhecimento do governo federal.

Com o Decreto-Lei n. ${ }^{\circ} 3.617$, de 15 de setembro de 1941, referente ao esporte na universidade, o Estado institui, inclusive, as diretrizes que a CBDU deve preconizar. Dessa forma, dentre outras determinações, define a criação de uma associação atlética acadêmica, constituída por alunos, e destinada à prática de desportos e à realização de competições desportivas em cada estabelecimento de ensino superior; a obrigatoriedade das associações atléticas acadêmicas de formarem uma federação atlética acadêmica anexada ao diretório central acadêmico da universidade e, dessas federações, se articularem e formarem a Confederação dos Desportos Universitários.

O esporte em seus diversos segmentos - militar, operário, estudantil, alto rendimento - tem sua tutela estatal apregoada em meio ao Estado Novo, na Ditadura Vargas, com a instituição do Decreto-Lei n 3.199 , de abril 1941. Esse documento cria o 
Conselho Nacional de Desporto (CND), que tem como missão “orientar, fiscalizar e incentivar a prática de desporto no país"15.

Com a definição dos princípios que devem ser seguidos pelo CND, o Estado consegue sujeitar as entidades esportivas aos seus interesses. A partir da regulamentação do esporte através dessa lei, que mantém suas características originais até o início dos anos de 1990, o Estado e o governo conseguem "legitimar e dispor tanto dos instrumentos legais quanto das estruturas institucionais para definir os rumos do esporte no Brasil e a participação desse setor na construção do Estado capitalista brasileiro" (VERONEZ, 2005, p.172). Assim, essa lei interferiu diretamente na "regulamentação das entidades esportivas; na definição da função do Estado brasileiro frente ao esporte; e na indicação de como administrar as práticas esportivas” (STAREPRAVO, 2005, p.44).

Esse decreto evidencia um caráter disciplinador nacionalista e moralizante do esporte. Protagonizando uma perspectiva centralizadora do Estado e um caráter eminentemente elitista, torna-se profundamente institucionalizado, configurando-se como reprodutor e disseminador dos valores da ideologia dominante, ignorando e negligenciando a prática esportiva pelo povo (CASTELLANI FILHO, 1994; MANHÃES, 2002).

No período que segue, do fim do Estado-Novo ao princípio da Nova República, a exemplo da iniciativa de Hitler, que utilizou o esporte como aparelho políticoideológico, o Brasil faz uso deste mesmo recurso, como expoente de desenvolvimento e reconhecimento no cenário internacional. Figurando como forte instrumento a serviço do Estado, no período da ditadura militar, juntamente com outras ações coercitivas e de

\footnotetext{
15 Decreto-Lei n³.199, de 14 de abril de 1941. Disponível em: < $\underline{\text { http://www.6.senado.gov.br/sicon/ }>~}$ Acesso em: 31 jul. 2010.
} 
controle social, o esporte é utilizado como instrumento de veiculação da ideologia do regime militar.

Dentre as ações instituídas no setor do esporte, destaca-se a introdução da Educação Física pautada no desenvolvimento esportivo como disciplina de caráter obrigatório no Ensino Superior.

Ao resgatar ações implementadas com o viés do controle social no âmbito do esporte educacional, Tubino (1996) destaca a realização dos Jogos Estudantis Brasileiros e os Jogos Universitários Brasileiros, e o apoio de associações atléticas nas universidades.

Castellani Filho (1994, p.121), ao escrever sobre a história da Educação Física brasileira, destaca que, no ensino superior, a presença da disciplina tinha como finalidade específica o "esvaziamento de qualquer tentativa de rearticulação política do movimento estudantil". Evidenciavam-se, dessa forma, os traços alienados e alienantes absorvidos pela “personagem” vivida pela Educação Física.

A maneira como as atividades físicas foram propostas e o caráter competitivo com o qual foram instituídas, bem como a valorização do brasileiro-desportista, além de evidenciar as fortes estratégias de governo para o controle e desmobilização da comunidade universitária, também acarretaram a descaracterização e destituição do significado e do papel da Educação Física enquanto componente de formação do homem através da dimensão corporal.

Se na época o esporte universitário devia, como relembra Castellani Filho (1994, p.124), cumprir a "função de envolver os estudantes em práticas esportivas e lúdicas como uma ação estratégica de distração para contrapor e/ou controlar as práticas políticas militantes de combate ao poder militar" atualmente, a situação mudou 
drasticamente. Da obrigatoriedade à prática desportiva como alternativa à ação política passou a ser quase que negligenciada nos campi. Foram reduzidos os incentivos às práticas desportivas competitivas, foram limitadas as oportunidades de práticas corporais enquanto forma de aprendizagem cultural, e são escassos os programas organizados na perspectiva da formação humana e do usufruto da vivência lúdica.

Starepravo et al (2010), ao realizarem um estudo sobre o esporte universitário e a Federação Paranaense de Desporto Universitário, e a relação desses com o Estado, discorrem que após vivenciar um período de crise a partir do final da década de 1980 , até início dos anos 2000, o esporte universitário passa por uma transição. Com a criação do Ministério dos Esportes, no primeiro mandado do presidente Luiz Inácio Lula da Silva, foi criada a divisão do Esporte Universitário.

Segundo os autores, o governo federal, na tentativa de reorganizar a CBDU, interfere diretamente na eleição dessa e a vincula ao $\mathrm{COB}$, com o intuito de viabilizar uma fonte de recursos (conforme prevista na Lei n. ${ }^{\circ} 10.264$, de 16 de julho de 2001, conhecida como Lei Agnelo/Piva) e apontar um novo modelo de financiamento ao esporte universitário. Destacam que além dos recursos provenientes da Lei Agnelo/Piva, o COB estabelece a empresa Golden Cross como parceira da iniciativa privada (STAREPRAVO et al, 2010).

Starepravo et al (2010, p.142) denominam essa conformação de modelo híbrido, à medida que, a partir dessa iniciativa, "foram aliados os recursos de financiamento público com verbas provenientes da iniciativa privada". Os autores advertem que essa nova configuração do esporte universitário, ao implantar

[...] uma gestão profissional e valorizar as instituições de ensino superior nos Jogos podem fazer com que o esporte universitário passe a viver um momento condizente com as novas tendências do esporte 
mundial: a aproximação com o mundo dos negócios e desvinculação do Estado. (STAREPRAVO et al, 2010, p. 143).

Assim, o esporte universitário destaca-se, sobretudo, nas instituições privadas. Conforme destaca a Revista da Confederação Brasileira de Desporto Universitário (BRASIL, 2008), o esporte é tido como um instrumento de educação, socialização e, principalmente, um investimento. Enfatiza, a partir da fala de um gestor de uma universidade particular, que o incentivo à prática esportiva além de complementar a formação acadêmica e o desenvolvimento social dos alunos, permite que muitos jovens tenham acesso ao ensino superior, graças às bolsas de incentivo, possibilitando, através dos resultados de equipes e atletas em torneios universitários, campeonatos nacionais e, até, Pan-Americanos e Olimpíadas, gerar visibilidade para as IES na mídia. Nesse modelo de organização são estabelecidas parcerias entre faculdades, clubes e prefeituras.

Além de desenvolver-se majoritariamente nas instituições privadas, o esporte universitário ao estar vinculado ao $\mathrm{COB}$ assume fortemente uma conotação de esporte de rendimento, distanciando-se consideravelmente das manifestações esportivas acessíveis a todos os interessados. Assim, ao se voltar ao desporto de rendimento, as práticas desportivas universitárias incorporam as diretrizes dessa forma de manifestação do esporte, qual seja a "orientação para o rendimento e a competição, a cientifização do treinamento, a organização burocrática, a especialização de papéis, a seleção e a desigualdade" (BRACHT, 1997, p.97).

Nas instituições públicas, as atividades relacionadas ao esporte e ao lazer, em geral, são fomentadas por iniciativas extensionistas de caráter esporádico ligadas, principalmente, aos programas de assistência estudantil (MARIN, et al, 2009). As instituições oferecem atividades de extensão variadas que são desenvolvidas através de 
projetos com datas pré-estabelecidas para início e término, deixando a continuidade dos projetos à mercê da vontade dos docentes responsáveis ou da renovação desses pelos órgãos competentes. Essas iniciativas são denominadas por Zigoni (1998, p.34) de "políticas de atividade".

Atualmente, na tentativa de minimizar o problema da falta de espaços/tempo públicos de modo a assegurar o direito às populações e democratizar o acesso às manifestações de esporte e lazer, o governo federal tem proposto diferentes programas vinculados ao Ministério do Esporte e gerenciados pela Secretaria Nacional de Desenvolvimento do Esporte e do Lazer. Programas como o Segundo Tempo (PST) e o Esporte e Lazer na Cidade (PELC) recentemente têm estabelecido aproximações e vêm sendo implementadas versões-piloto em instituições de ensino superior.

O Programa Segundo Tempo ${ }^{16}$, desenvolvido em âmbito nacional, desde 2003, tem como público-alvo crianças e adolescentes dos sete aos dezessete anos. Objetiva integrar o indivíduo à sociedade através da prática esportiva e de atividades complementares no turno oposto ao das aulas na escola; proporcionar ao indivíduo a possibilidade de atingir um desenvolvimento de valores sociais, melhoria das capacidades físicas e motoras, integração social; além de afastar a criança e o adolescente das drogas, prostituição, criminalidade e outros riscos sociais provenientes do meio em que muitos deles vivem.

No ano de 2009, o Ministério do Esporte lança o Projeto-Piloto Universitário do Programa Segundo Tempo ${ }^{17}$, no qual foram contempladas quatro universidades, sendo elas: Universidade Federal de Santa Maria (UFSM), Universidade de Brasília (UnB),

\footnotetext{
${ }^{16}$ Disponível em http://www.esporte.gov.br/snee/segundotempo/default.jsp. Acesso em: 15 dez.2010.

17 As informações aqui apresentadas são dos sites http://jararaca.ufsm.br/websites/segundotempo, \# http://web3.ufes.br/sis/node/104. Acesso em: 19 nov. 2010 Obs.: Até a data deste acesso, no site do Ministério do Esporte não foram localizadas informações referentes ao programa.
} 
Universidade Federal de Minas Gerais (UFMG), em Belo Horizonte, e Universidade Federal de Ouro Preto (UFOP), também em Minas Gerais.

A proposição do Ministério do Esporte, das universidades e da Secretaria Nacional de Esporte Educacional parte do entendimento de que o Segundo Tempo Universitário contribui para resgatar a prática esportiva e incitar a inserção do esporte no projeto pedagógico das Instituições de Ensino Superior.

A recente iniciativa do Ministério do Esporte em fomentar a implantação de programas de esporte e lazer nas universidades representa um grande avanço. É necessário, no entanto, ter presente que essas ações são instituídas por programas de um determinado governo, o que as torna frágeis diante de uma possível troca de gestão. Nessa perspectiva, para que sejam asseguradas ações de fomento ao esporte e lazer na universidade é necessário que estas façam parte do planejamento, do projeto pedagógico institucional, convertendo-se em políticas institucionais, gestionadas internamente.

\section{Políticas de esporte e lazer nas universidades federais brasileiras a partir dos documentos oficiais}

A universidade, ao coadunar estrutura e valores perpetuados pela sociedade civil, traz no bojo de seus documentos oficiais concepções sobre sua missão, funcionamento, prioridades e inserção local, descrevendo políticas e estratégias institucionais e estabelecendo metas a serem alcançadas que servirão como cerne da identidade institucional.

Ao tomarmos como objeto de estudo as questões relacionadas ao esporte e o lazer, apresentaremos como essas figuram nos documentos (PDI,PPI, REUNI) tomando como ponto de partida a frequência com que a temática do esporte e lazer é abordada, a forma como é mencionada/redigida e a que aspectos/ setores se referem. 
A consulta ao material coletado nos possibilitou apontar que todas as universidades selecionadas, em pelo menos em um dos seus documentos, exprimem ideias relacionadas ao esporte e lazer, sendo o PDI o documento que mais apresenta aspectos relacionados à temática. Entre as quinze universidades investigadas, apenas uma não faz referência ao esporte e ao lazer nesse documento.

Os apontamentos aludem, preponderantemente, ao esporte e lazer como estratégia de assistência estudantil e como elementos a serem contemplados na melhoria da infraestrutura institucional. São mencionados também como mecanismo de interação com a comunidade externa e entre a comunidade interna e de melhoria das condições de trabalho dos servidores. Apenas uma das instituições aponta o esporte e lazer como um direito social, constitucionalmente garantido indispensável para a formação cidadã e outras duas mencionam o esporte e lazer em categorias gerais. Através do quadro abaixo buscamos ilustrar esse panorama.

QUADRO1

\begin{tabular}{|c|c|c|c|c|c|}
\hline $\begin{array}{l}\text { Universidades/ } \\
\text { Apontamentos }\end{array}$ & $\begin{array}{l}\text { Assistência } \\
\text { Estudantil }\end{array}$ & $\begin{array}{l}\text { Interação comunidade } \\
\text { interna/ externa }\end{array}$ & $\begin{array}{l}\text { Melhoria condições } \\
\text { de trabalho }\end{array}$ & $\begin{array}{l}\text { Infra } \\
\text { Estrutura }\end{array}$ & $\begin{array}{l}\text { Direito } \\
\text { social }\end{array}$ \\
\hline Universidade A & & $\mathrm{X}$ & & $\mathrm{X}$ & \\
\hline Universidade B & $X$ & $\mathrm{X}$ & & $\mathrm{X}$ & \\
\hline Universidade C & $\mathrm{X}$ & & & & \\
\hline Universidade D & $\mathrm{X}$ & & & & \\
\hline Universidade $\mathbf{E}$ & $\mathrm{X}$ & $\mathrm{X}$ & & $\mathrm{X}$ & \\
\hline Universidade F & & & & & $X$ \\
\hline \multicolumn{6}{|l|}{ Universidade G } \\
\hline Universidade $\mathbf{H}$ & $\mathrm{X}$ & & & $X$ & \\
\hline Universidade I & & & & $\mathrm{X}$ & \\
\hline Universidade $\mathbf{J}$ & & & & $\mathrm{X}$ & \\
\hline \multicolumn{6}{|l|}{ Universidade L } \\
\hline Universidade M & $\mathrm{X}$ & & $X$ & $X$ & \\
\hline Universidade $\mathbf{N}$ & $\mathrm{X}$ & & $\mathrm{X}$ & $X$ & \\
\hline Universidade $O$ & $\mathrm{X}$ & $\mathrm{X}$ & $\mathrm{X}$ & & \\
\hline Universidade $\mathbf{P}$ & $X$ & $X$ & $X$ & $X$ & \\
\hline
\end{tabular}


Buscando compreender a composição do QUADRO acima a luz das orientações que vem conformando a Educação Superior atualmente, destacamos que a forte associação das manifestações de esporte e lazer a estratégias de assistência estudantil evidenciada no quadro acima, pode estar atrelada aos indicativos presentes na atual política de assistência estudantil.

Embora tanto a Constituição Federal de 1988 quanto a LDB 9394/96 enunciem como direito de qualquer cidadão a igualdade das condições de acesso e permanência ao ensino apenas recentemente a assistência ao estudante vem tornando-se objeto de preocupação por parte do poder público.

Com a implantação do REUNI, que estabelece entre as suas metas a ampliação do acesso e permanência de alunos no ensino superior, tornou-se necessário estabelecer diretrizes voltadas ao amparo do estudante para viabilizar tal propósito. Assim, o Decreto-Lei $\mathrm{n}^{\mathrm{o}}$ 6.096, de 24 de abril de 2007, que o institui, ao trazer em seu Art. $2^{\circ}$ inciso V a "ampliação de políticas de inclusão e assistência estudantil" como uma de suas diretrizes, obriga as universidades a buscarem alternativas para atingirem essa meta.

Em consonância com essa diretriz do REUNI, em dezembro de 2007, é instituído pelo Ministério da Educação a Portaria Normativa $n^{\circ} 39$ referente ao Programa Nacional de Assistência Estudantil (PNAES). O PNAES estabelece como objetivos:

I- democratizar as condições de permanência nas IFES; II-minimizar os efeitos das desigualdades sociais e regionais na permanência e conclusão da educação superior; III-reduzir as taxas de retenção e evasão; e IV-contribuir para a promoção da inclusão social pela educação. (BRASIL, 2007). 
Institui como "ações de assistência estudantil iniciativas desenvolvidas nas seguintes áreas: moradia, alimentação, transporte, assistência à saúde, inclusão digital, cultura, esporte, creche e apoio pedagógico” (BRASIL, 2007, grifo nosso).

Ao analisarmos os documentos (PDI, PPI,REUNI) das instituições investigadas podemos perceber que as premissas enunciadas no PNAES foram incorporadas nas proposições de algumas instituições. No que tange ao esporte e lazer, esse é mencionado juntamente com um conjunto de condições a serem garantidas aos acadêmicos. Em alguns casos, há apenas a reprodução na íntegra do texto do PNAES sem apresentação de qualquer estratégia de efetivação.

Outras universidades, no entanto, tomam esses apontamentos como ponto de partida para sinalizarem ações de esporte e lazer relacionadas à assistência estudantil. Nessa direção, mencionamos a Universidade B e a Universidade N.

A primeira assinala o acesso à cultura, ao esporte e ao lazer como "sendo fundamentais à formação cidadã dos profissionais e como instrumento de promoção da qualidade de vida" (UNIVERSIDADE B). Ressalta a necessidade da promoção de programas culturais, esportivos e de lazer e elenca uma série de atividades ${ }^{18}$ a serem mantidas e implementadas. Destacam-se o planejamento de diversos festivais culturais, de música, jogos, campeonatos e apresentações de grupos artísticos da universidade.

A Universidade $\mathrm{N}$ apresenta em seu PDI “a prática do desporto universitário, como elemento de integração e de inserção acadêmica" assegurando a necessidade de definir uma Política de Desporto Universitário. Além de objetivar a estruturação do Programa "Atleta de Alto Desempenho", elenca a realização de festivais, jogos e campeonatos.

\footnotetext{
18 Todas as atividades estão nominadas nos documentos da instituição, entretanto, preferimos não mencioná-las nominalmente para preservar o anonimato.
} 
As demais instituições (D, E, H, M, P), embora associem as manifestações de esporte e lazer às estratégias de assistência estudantil, o fazem de forma genérica e não propositiva. Assim, nos diferentes documentos, no tópico assistência estudantil, as menções ao esporte e lazer são, em sua maioria, em sentenças soltas no texto, evidenciando a prevalência de sentido mais próximo ao senso comum.

Afirmações como "possibilitar o acesso a serviços, cultura, esporte e lazer para estimular a permanência dos estudantes na universidade” (UNIVERSIDADE E), "promover a humanização do campus através de atividades culturais, seminários voltados à integração social e o lazer" (UNIVERSIDADE D) ou ainda, "apoiar a prática de esportes e lazer e a realização de eventos esportivos” (UNIVERSIDADE M) são bastante ilustrativas.

As enunciações relacionadas ao tema, em geral, são apresentadas por verbos como apoiar, incentivar, possibilitar, os quais evidenciam uma postura de isenção, de desobrigação da universidade com a promoção de ações relacionadas ao esporte e lazer. O emprego desses verbos remete a ideia de que a responsabilidade da proposição é de outrem. Assim, as IES se colocam no papel de incentivadoras, eximindo-se da função de proponente.

Transcendendo o âmbito da assistência estudantil, acreditamos que a democratização do acesso aos bens culturais - a partir da proposição de experiências de esporte e lazer - pode constituir-se um veículo de interação entre universidade comunidade.

O entendimento que essas podem viabilizar uma maior aproximação entre as IES e comunidade em que está inserida é explicitado, textualmente, nos documentos de algumas das instituições investigadas. Como demonstrado no quadro, cinco 
universidades sinalizam esporte e lazer como um mecanismo de interacão com a comunidade externa e integração da comunidade interna entre si, conforme exemplificam os trechos abaixo:

Além da pesquisa e da extensão, outros mecanismos de interação com a comunidade também devem ser postos em ação como: programas de educação continuada; programas de dinamização da cultura e difusão do esporte e lazer [...]. Os programas de esporte e lazer, voltados para qualidade de vida, devem oportunizar a comunidade interna e externa a prática de atividades físicas como fator de saúde, estimulando o desenvolvimento de hábitos saudáveis de vida, além da criação e difusão das expressões artístico-culturais, viabilizando o acesso da comunidade aos espaços culturais, desportivos e de lazer. (UNIVERSIDADE A, PDI)

Meta: Integração Universidade-Comunidade. Estratégia: planejar e operacionalizar a Universidade Aberta, nos finais de semana para desenvolver ações de educação, cultura e lazer para a comunidade do entorno (sic.) dos campi. (UNIVERSIDADE O, PDI)

Embora figurem em menor número as referências relativas à interação com a comunidade, podemos destacar que no que se refere à relação com a comunidade externa os apontamentos são mais objetivos e menos evasivos do que os concernentes a assistência estudantil.

Os registros, assinalados no tocante à Extensão Universitária, trazem a proposição de programas, implementação e revitalização de ações anteriormente desenvolvidas pelas instituições. É possível constatar que as quatro instituições propõem-se a criar pelo menos um programa voltado à temática, ainda que não façam qualquer alusão mais detalhada sobre isso na documentação consultada.

Cabe destacar que a Universidade E, refere-se majoritariamente, a garantia de uma infraestrutura adequada para o desenvolvimento de ações culturais. Ainda que sinalize a criação de um programa voltado à cultura, o texto remete a ideia de que a instituição se preocupa com a oferta do espaço e coloca-se mais na função de apoiadora 
do que proponente de ações. A utilização frequente dos verbos apoiar, estimular, fomentar, denota como referimos anteriormente, um caráter descompromissado por parte da instituição, no que concerne a proposição de experiências relacionadas ao esporte e lazer tanto para a comunidade interna quanto externa.

A Universidade $\mathrm{P}$, todavia, além de mencionar a criação de um programa de atividade física para a instituição e a criação de várias companhias artísticas, é a única que faz alusão à destinação de recursos financeiros para o fomento de atividades esportivas, mesmo que não elucide a fonte de tais recursos.

Embora, textualmente, as explicitações envolvendo as manifestações de esporte e lazer no âmbito da extensão universitária soem mais consistentes e propositivas do que as concernentes a assistência estudantil, o que podemos constatar é que todas as instituições que as referendam o fazem em um rol de possíveis ações a serem implementadas, entretanto, não enunciam de que forma operacionalizarão tais proposições.

Não há qualquer menção sobre recursos financeiros a serem destinados, sobre quais instâncias institucionais serão requeridas, ainda que se pressuponha que sejam as Pró-Reitorias específicas de cada segmento (Pró- Reitoria de Extensão, Pró- Reitoria de Assistência Estudantil, Pró- Recursos Humanos, etc.). Os centros de ensino como os de Educação Física, Artes, Educação entre outros não são sinalizados como possíveis parceiros no planejamento e desenvolvimento de ações, bem como não são indicados quem serão os possíveis sujeitos (acadêmicos, docentes, técnicos administrativos, parceiros de outras instituições, etc.) que darão concreticidade as ações.

A escassa menção a extensão universitária, especialmente no que tange a temática estudada, em nosso entendimento, coaduna com o atual processo de reforma 
das IFES. Conforme destacam Léda e Mancebo (2009), o fato das "Diretrizes do REUNI" citarem apenas em um momento as "Políticas de Extensão Universitária", como uma dimensão do compromisso social da instituição, remonta sem meias palavras que

[...] a expansão desejada e 'financiada' é só para o ensino, seguindo antigas lições do World Bank (1994),que além de condenarem a predominância das universidades de pesquisa (humboldtianas) - uma realidade que nunca existiu no sistema de educação superior brasileiro - propunham as universidades de ensino (que se ocupariam do ensino ou da formação neoprofissional), mais adequadas aos países com déficit público crônico (LÉDA e MANCEBO, 2009, p. 55).

Outro aspecto bastante citado nos documentos analisados, diz respeito à infraestrutura destinada à vivência das manifestações de esporte e lazer. Localizamos nos documentos de nove instituições, apontamentos relacionados à revitalização e ampliação da estrutura física necessária para práticas desportivas e de lazer. A preocupação com a infraestrutura apresenta-se nos documentos estudados, majoritariamente, atrelada ao cumprimento das metas referentes à assistência estudantil e a extensão universitária. Em alguns casos, a única meta mencionada para viabilizar o esporte e lazer refere-se à estrutura física como demonstra o seguinte trecho:

Eixo: Assistência Estudantil. Meta: Criar condições aos alunos para uma maior inserção na vida acadêmica. Estratégia para atingir a meta: [...] Criar condições adequadas para que o estudante permaneça no ambiente universitário, por meio da ampliação de espaços para leitura e práticas esportivas, atividades culturais e de lazer (REUNI, UNIVERSIDADE J, 2008).

Não obstante, reconhecemos que o espaço é um dos elementos fundamentais para a vivência das manifestações de esporte e lazer à medida que essas dependem do ambiente e equipamentos onde ocorrem, podendo esses ser específicos ou não 
específicos. Parece-nos, no entanto, que não é esse o entendimento que, preponderantemente, baliza essa preocupação.

Como o REUNI estabelece entre suas diretrizes a redução das taxas de evasão, ocupação de vagas ociosas, aumento de vagas de ingresso, especialmente, no período noturno e a ampliação de políticas de inclusão e assistência estudantil indica que os recursos financeiros serão reservados aquelas universidades que cumprirem as metas. Destaca-se entre essas a construção e readequação de infraestrutura e equipamentos necessários à realização dos objetivos do Programa (BRASIL, 2008). Se o esporte e lazer são indicados como estratégias de promoção da inclusão e assistência estudantil considerando a referida meta acerca da destinação de recursos - logo devem ser criadas condições físicas adequadas para tal.

As menções relacionadas ao fomento da cultura, esporte e lazer como estratégia de assistência ao servidor e melhoria das suas condicõos de trabalho que foram localizados nos documentos analisados, também se apresentam a mesma condição concernente a assistência ao estudante e a extensão universitária. A exemplo, dessas é possível perceber que não há proposições efetivas que contemplem os técnicosadministrativos. O que encontramos são indicativos de possíveis iniciativas. Os textos das Universidades $\mathrm{N}$ e $\mathrm{P}$ remetem a ideia de que já existe alguma ação sendo desenvolvida, entretanto, não apresentam maiores detalhamentos.

Consolidar o Programa de Qualidade de Vida no Trabalho Atividades: Retomar ações do Programa de Educação Física Esporte e Lazer. (PDI, Universidade N)

Aprimorar programas de assistência ao servidor. Metas: Ampliar a assistência ao servidor e seus dependentes. Ações: viabilizar atividades de lazer e cultura. (natação, música, hidroginástica, etc...) (PDI, Universidade P) 
Embora todas as instituições investigadas referenciem o esporte e o lazer em seus documentos, a falta de precisão no trato das questões relativas a esses revela a inexistência de políticas institucionais voltadas para essa dimensão, na grande maioria dessas. Tal como explicam Santos e Amaral (2010, p.4)

[...] uma definição política indica-nos os modos de dar materialidade a uma concepção teórica de lazer, e está a ela intrinsicamente ligada; determina qual, ou quais as instituições responsáveis pela política, qual sua fonte de financiamento, quais suas diretrizes, mecanismos, princípios e objetivos.

A medida que nenhuma das instituições mencionadas referenda os preceitos sinalizados pelas autoras podemos afirmar que essas além de não possuírem uma política institucional de esporte e lazer, desconsideram o potencial formativo desses e não reconhecem como sua responsabilidade a democratização dos bens culturais, nesse caso, relacionados as manifestações de esporte e lazer.

Em contraposição ao que foi explicitado até então, é necessário destacar o caso da Universidade F. Essa, diferentemente das demais instituições expressa claramente uma preocupação com a democratização das manifestações culturais ao assinalar que:

[...] na universidade contemporânea, a cultura representa valor essencial para a constituição e promoção da cidadania e deve não só ser considerada um gênero de primeira necessidade, mas também estar comprometida com a transformação da realidade, por ser aglutinadora em todas as suas dimensões. (PDI, UNIVERSIDADE F).

Reconhece que a cultura, ao exercer as funções de formadora e expoente das manifestações individuais e coletivas da humanidade, desdobra-se em diversas formas que podem ser pensadas a partir de pelo menos três eixos de desenvolvimento: "as ações sociocomunitárias, as manifestações artísticas e as atividades de lazer" que podem estar interligados entre si (PDI, UNIVERSIDADE F). 
Salienta que a busca pela pluralidade de manifestações que a sociedade engendra, especialmente, no que diz respeito àqueles sujeitos situados à margem dos processos interculturais, sociais e políticos justifica-se pela importância de enfocar

[...] a diversidade e a criatividade político-cultural, as experiências coletivas que conformam a história das práticas sociais, na busca de estabelecer uma troca com a comunidade e de potencializar a produção cultural e a construção da cidadania, entendida, nesse caso, como um conjunto de direitos e deveres políticos, civis e sociais do indivíduo perante a sociedade. Entre esses direitos sociais, destacamse os culturais [...] esse conjunto de direitos compõe a noção de cidadania cultural, componente indispensável da plena cidadania. (PDI, UNIVERSIDADE F).

Para concretizar tal entendimento, essa universidade prevê um projeto de ação cultural que vislumbra materializar a política e as ações culturais da instituição. Embora não sejam esmiuçadas no documento as particularidades de cada ação elencada, consideramos um diferencial toda a proposta e fundamentação apresentada por esta instituição. Essa é a única que destaca o esporte e o lazer como direitos sociais constitucionalmente garantidos e reconhece a sua responsabilidade em relação à garantia do acesso a esse direito pela comunidade, não os atrelando ao atendimento de outras necessidades (assistência estudantil, assistência ao trabalhador, etc.).

\section{Considerações Finais}

Ao buscar discorrer sobre a importância de instituir a universidade enquanto espaço de promoção e vivência de manifestações de esporte e lazer, trazendo-os à discussão como objeto de estudo no âmbito das universidades federais, a partir da análise de seus documentos foi possível destacar algumas reflexões e tecer considerações preliminares sobre tal temática. 
A relação das universidades brasileiras com o esporte e lazer, por datarem de longo tempo, evidenciam que até a década de 1940 essas manifestações emergiam no bojo das instituições universitárias sem interferência direta do Estado. Atualmente, apesar de haver um movimento mais consolidado do governo federal em direção ao fomento do esporte de rendimento e uma recente iniciativa de incentivo ao esporte e lazer através da implantação de Programas Piloto (PST, PELC) em algumas universidades federais, não se encontrou ressonância por parte das instituições universitárias federais às políticas adotadas.

As IFES, de maneira geral, não trazem em seus documentos alusões convergentes a essas políticas nem assinalam proposições de outra natureza (vivências de esporte e lazer). Embora todas as universidades englobadas na investigação façam referência a esporte e lazer em seus documentos, especialmente mencionando a necessidade de apoiar, incentivar essas manifestações, não sinalizam, no entanto, a quais atividades se referem, e não prevêem propostas objetivas.

Em virtude da natureza da pesquisa (bibliográfica e documental), cabe ponderar que ações pontuais ou derivadas dos diferentes cursos (centros) que compõem as IES, no que tange a esporte e lazer, escapam do foro desta investigação. Também, a existência do registro documental não garante a efetivação de ações concretas. No entanto, reitera-se que expressar a preocupação com o esporte e o lazer na elaboração de suas políticas e enunciar proposições objetivas pode sinalizar a importância que as universidades atribuem a essas manifestações enquanto veículo de formação, já que tanto orientam a comunidade interna quanto influenciam e externa.

Nessa direção, o esporte e o lazer, ao estarem inseridos na pauta de preocupações das universidades, especialmente na redação de seus documentos, poderá 
evidenciar uma forma de essas instituições se comprometerem com a vida social do lugar onde estão inseridas e a de se articularem com a sustentação e a garantia dos direitos humanos.

Desse modo, esse comprometimento com a democratização de bens culturais pode - a partir da proposição de experiências de esporte e lazer - vir a se configurar numa possibilidade concreta de as universidades fortalecerem os laços com a comunidade interna e externa, de se constituírem como espaço aberto a diferentes práticas educativas, de viabilizarem um estreitamento entre a teoria e a prática social, e de recobrarem sua vocação enquanto promotora da emancipação humana, intensificando assim sua relevância social.

\section{REFERÊNCIAS}

ALMEIDA, B.S.; MARCHI JUNIOR, W. O financiamento dos programas Federais de esporte e lazer no Brasil (2004 a 2008). Revista Movimento, Porto Alegre, v. 16, n. 04, p. 73-92, out/dez, 2010.

AMARAL, S. C. F. Políticas Públicas de Lazer: existe possibilidade de uma gestão participativa? In: PADILHA, V. (Org.). Dialética do Lazer. São Paulo: Cortez, 2006. p.156-172.

BRACHT, V. Sociologia crítica do esporte: uma introdução. Vitória: UFES: Centro de Educação Física e Desporto, 1997.

BRASIL. Constituição (1988). Constituição da República Federativa do Brasil: promulgada em 5 de outubro de 1988. Disponível em: http://www.planalto.gov.br/ccivil 03/constituicao/constitui\%C3\%A7ao.htm>. Acesso em: 17 jun. 2010.

BRASIL. Decreto Lei ${ }^{\circ} \mathbf{6 . 0 9 6}$ de 24 de abril de 2007. Institui o Programa de Apoio a Planos de Reestruturação e Expansão das Universidades Federais - REUNI. Disponível em: http://www.planalto.gov.br/ccivil 03/_ato2007-2010/2007/decreto/d6096.htm.

Acesso em: 20 de ago. 2010. 
BRASIL. Decreto Lei ${ }^{\circ} \mathbf{1 0 . 2 6 4}$ de 16 de julho de 2001. Acrescenta inciso e parágrafos ao artigo 56 da lei 9.615, de 24 de março de 1998, que institui normas gerais sobre desporto. Diário Oficial da República Federativa do Brasil. Brasília DF, 17 jul. 2001a. Disponível em: <http://www6.senado.gov.br/legislacao/ ListaPublicacoes.action?id=233173>. Acesso em: 17 jun. 2010.

BRASIL. Diretrizes do REUNI. Brasília, 2008. Disponível em: portal.mec.gov.br/sesu/arquivos/pdf/diretrizesreuni.pdf. Acesso em: 24 ago. 2010.

BRASIL. Decreto-Lei n. 3.199, de 14 de abril de 1941. Rio de Janeiro, 1941. Dispõe sobre as bases de organização dos desportos em todo pais. Disponível em: $<$ http://www6.senado.gov.br/sicon>. Acesso em: 31 jul. 2010.

BRASIL. Decreto-Lei n. ${ }^{\circ}$ 3.617 de 15 de setembro de 1941. Dispõe sobre as bases de organização dos desportos universitários. Disponível em:

$<$ http://www.jusbrasil.com.br/legislacao/126690/decreto-lei-3617-41 > . Acesso em: 28 jul. 2010.

BRASIL. Decreto-Lei n. ${ }^{\mathbf{0} 421}$ de 11 de maio de 1938. Regula o funcionamento dos estabelecimentos de ensino superior. Disponível em: $<$ http://www2.camara.gov.br/legin/fed/declei/1930-1939/decreto-lei-421-11-maio-1938350759-publicacao-1-pe.html>. Acesso em: 31 jul. 2010

BRASIL. Lei de Diretrizes e Bases da Educação Nacional de 20 de dezembro de 1996. Estabelece as diretrizes e bases da educação nacional Disponível em: <www.planalto.gov.br/ccivil 03/Leis/L9394.htm> Acesso em: 20 out. 2010

BRASIL. Portaria Normativa $\mathbf{n}^{0}$ 39, de 12 de dezembro de 2007. Institui o Programa Nacional de Assistência Estudantil - PNAES. Disponível em: portal.mec.gov.br/arquivos/pdf/portaria_pnaes.pdf. Acesso em: 18 jan. 2012.

BRASIL. Revista da Confederação Brasileira de Desporto Universitário

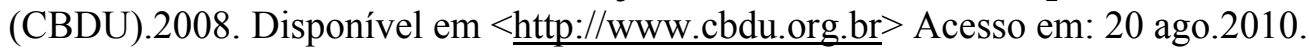

CASTEllani FILHO, L. Educação Física no Brasil: a história que não se conta. 4. ed. Campinas: Papirus, 1994.

CATANI, A. M.; LIMA, L.; AZEVEDO, M.N. O Processo de Bolonha, a avaliação da Educação Superior e algumas considerações sobre a Universidade Nova. Revista da Avaliação da Educação Superior, v. 13, n. 1, mar., 2008. p. 7-37. Disponível em: $<$ http://redalyc.uaemex.mx/redalyc/pdf/2191/219114876002.pdf $>$ Acesso em: 15 nov. 2010 .

FERREIRA, S. Reforma da Educação Superior no Brasil e na Europa. Em debate os novos papéis sociais para as universidades. In: REUNIÃO ANUAL DA ANPED, 33, Caxambu (MG), 2010. Disponível em: <www.anped.org.br/33encontro/app/webroot/files/file/.../GT11-6003--Int.pdf. $>$. Acesso em: 30 nov. 2010. 
IBGE. Pesquisas de Informações Básicas Municipais: Perfil dos Municípios Brasileiros/Cultura 2006. Rio de Janeiro: Instituto Brasileiro de Geografia e Estatística, 2007.

http://www.ibge.gov.br/home/estatistica/economia/perfilmunic/cultura2006/cultura2006 .pdf $>$ Acesso em: 10 jan. 2010.

LÉDA, D.B; MANCEBO, D. Reuni: heteronomia e precarização da universidade e do trabalho docente. Educação e Realidade v. 34, n 1. p. 49-64. 2009.

LIMA, K. Contra-reforma da educação nas universidades federais: o REUNI na UFF. Associação dos Doentes da UFF (ADUFF). Artigo apresentado na Seção Observatório da Universidade de 17 de set. de 2009. Disponível em: $<$ www.aduff.org.br/especiais/download/20090917 contra-reforma.pdf $>$ Acesso em: 14 out. 2010.

MANHÃES, E.D. Políticas de Esporte no Brasil. Rio de Janeiro: Paz e Terra, 2002.

MARCELLINO, N.C. O Lazer e o Espaço da Cidade. In: ISAYAMA, H.; LINHALES, M. A. (Org.). Sobre Lazer e Política: maneiras de ver, maneiras de fazer. Belo Horizonte: Editora da UFMG, 2006. p.65-92.

MARCELLINO, N.C. Lazer e Sociedade: algumas aproximações. In: Nelson Carvalho MARCELlinO, (Org.). Lazer e Sociedade: múltiplas relações. Campinas: Editora Alínea, 2008, p.11-26.

MARIN, E.C. et al. Políticas de Lazer nas Instituições de Ensino Superior: uma Discussão a partir da Práxis. In: ENCONTRO NACIONAL DE RECREAÇÃO E LAZER, 19. Florianópolis, 2009. Anais... Florianópolis, 2009.

MULLER, Pierre; SUREL, Yves. Análise das políticas públicas. (tradução de Agemir Bavaresco e Alceu R. Ferraro). Pelotas: Educat, 2002.

PARO, Victor H. Por dentro da escola pública. São Paulo: Xamã, 1995.

RODRIGUES, A. B. Lazer e espaço na cidade pós-industrial. Licere, Belo Horizonte, v.5, n.1. p.149-164, set. 2002.

SANTOS, F.C.; AMARAL, S.C.F. Sobre Lazer e Políticas Sociais: Questões TeóricoConceituais. Pensar a Prática, Goiânia, v. 13, n.3, p. 1-13, set/ dez, 2010.

SANTOS, B.S. A universidade do século XXI: para uma reforma democrática e emancipatória da Universidade. 3.ed. São Paulo: Cortez, 2010.

STAREPRAVO, F.A. O esporte universitário paranaense e suas relações com o poder público. Dissertação (Mestrado) - Educação Física. Departamento de Educação Física da Universidade Federal do Paraná (UFPR). Curitiba, 2005. 
STRAREPRAVO, F.A.; et al. Esporte Universitário Brasileiro: uma leitura a partir de suas relações com Estado. Revista Brasileira de Ciências do Esporte, Campinas, v.31, n.3, p. 131-148, maio 2010.

TUBINO, J. M.G. O Esporte no Brasil, do período colonial aos nossos dias. São Paulo: IBRASA, 1996.

VERONEZ, L.F.C. Quando o Estado joga a favor do privado: políticas de esporte após a Constituição de 1988. Tese (Doutorado) - Educação Física. Faculdade de Educação Física da Universidade Estadual de Campinas (UNICAMP), Campinas, 2005.

ZIGONI, P. Políticas Públicas participativas de esporte e lazer: da congestão à cogestão. Revista Motrivivência, v.10, n. 11, set/1998, p. 31-47.

\section{Endereço das Autoras:}

Gabriela Machado Ribeiro

R. Almirante Tamandaré, 251/302.

Centro - Pelotas - RS

CEP: 96010-750

Endereço Eletrônico: gabimacrib@yahoo.com.br

Elizara Carolina Marin

Universidade Federal de Santa Maria

Centro de Educação Física e Desportos

Avenida Roraima, $\mathrm{n}^{\circ} 1000$ - Cidade Universitária

Bairro Camobi - Santa Maria - RS

CEP: 97105-900

Endereço Eletrônico: gabimacrib@yahoo.com.br 